\title{
Quintais produtivos: para além do acesso à alimentação saudável, um espaço de resgate do ser
}

\author{
Backyards productive: beyond the access to healthy food, one being the rescue space
}

\author{
Adriella Camila G. Furtado da Silva ${ }^{1}$ \\ Mônica de Caldas Rosa dos Anjos ${ }^{2}$ \\ Adilson dos Anjos ${ }^{3}$
}

\begin{abstract}
Resumo
Esta pesquisa traz à discussão algumas das possíveis contribuições dos quintais produtivos, na melhoria da situação de Segurança Alimentar e Nutricional (SAN). Trata-se de uma pesquisa de campo, exploratória, de abordagem quantiqualitativa. Foram entrevistados 18 participantes e/ou famílias, por meio de entrevistas estruturadas, semiestruturadas e visitas domiciliares. Evidenciouse que a manutenção do quintal produtivo, proporciona às famílias condições para construção de sua própria capacidade, mesmo que em parte, de alimentar-se, conduzindo a melhores hábitos alimentares, sobretudo por conta da relação que fazem entre alimentação e saúde. Para além da produção de alimentos, salientam-se outras motivações para manutenção dos quintais produtivos, como: a questão cultural; econômica; o gostar e o prazer em plantar; a importância dada a valores, costumes e hábitos rurais, o cultivo como ocupação e terapia. No entendimento de que a situação de SAN depende da garantia de outros direitos para sua consolidação e, na compreensão de que os quintais produtivos podem ser uma via para construção de um espaço dialógico, de socialização e de resgate da autonomia e da autoestima, ressalta-se a necessidade de ações, projetos, programas e políticas que viabilizem e fortaleçam a existência desta estratégia, visando o empoderamento, a formação cidadã e política e a garantia do Direito Humano à Alimentação Adequada e Saudável, como consequência.
\end{abstract}

Palavras-chave: Quintal Produtivo, Segurança Alimentar e Nutricional, Saúde.

\begin{abstract}
This research brings to the discussion some of the possible contributions the productive backyards to the improving of the Food Security and Nutrition (FSN) situation. This is a field research, exploratory, of quantiqualitative approach. Eighteen participants and /or families participated of the research through structured interviews, semi-structured and home visits. It was evident that the maintenance of the productive backyards provides conditions for families to construct their own capacity to feed, leading to better eating habits, especially because of the relationship between food and health, even that in part. In addition to the production of food, emphasize up other motivations for the maintenance of productive backyards, as cultural issue; economic; the relish and pleasure of

\footnotetext{
${ }^{1}$ Nutricionista, Especialista em Saúde da Família pela Universidade Federal do Paraná (UFPR)/Modalidade Residência Multiprofissional.E-mail: adriellacamilafurtado@ hotmail.com.

${ }^{2}$ Nutricionista, Professora Adjunta do Departamento de Nutrição, UFPR. E-mail: mcranjos@yahoo.com.br.

${ }^{3}$ Engenheiro Agrônomo, Professor Adjunto do Departamento de Estatística, UFPR. E-mail: aanjos@ufpr.br.
} 
planting; the importance given to values, customs and rural habits, and the farming as an occupation and therapy. Understanding that the FSN situation depends on the guarantee of other rights for its consolidation and that productive backyards can be a way to build a dialogic space, socialization and recovery of autonomy and self-esteem, It is important to emphasize the necessity for actions, projects, programs and policies that support and strengthen the existence of this strategy, aimed at empowerment, political education and citizen and guarantee the human right to adequate food and healthy as a result.

Keywords: Productive Yard, Food Security and Nutrition, Health.

[...] o ato de alimentar-se, e de alimentar seus familiares e aos outros é um dos que mais profundamente reflete a riqueza $e$ a complexidade da vida humana na sociedade (VALENTE, 2002, p. 103).

\section{Introdução}

O modelo econômico brasileiro vigente, em meados do século XVIII, desencadeou toda uma reestruturação da sociedade aos moldes industriais, com o crescimento das cidades e a intensa industrialização da agricultura, ocasionando um processo de aglomeração urbana, concomitantemente ao esvaziamento demográfico das áreas rurais (REIS, 2006). Em decorrência deste modelo de crescimento agroindustrial excludente, verificou-se, como resultado social, a acentuação da concentração de renda e terras (GRAZIANO DA SILVA, 1993), assim como uma significativa redução de empregos e renda no campo, suscitando um processo crescente de exclusão dos agricultores que, por várias circunstâncias, dispunham de menor acesso aos fatores de produção como terra, trabalho e capital (REDIN; SILVEIRA, 2010).

A urbanização acelerada fez com que produtos do mundo inteiro se misturassem, delineando novas modalidades de consumo, transformando, progressivamente, os hábitos alimentares (MALUF; MENEZES, 2000; GARCIA, 2003). Esta influência global afetou muitas das pessoas que saíram da área rural para tentar a vida nas cidades, as quais abandonaram a alimentação mais diversificada (MALUF; MENEZES, 2000), e se depararam com a pobreza, exclusão e outros problemas sociais (CANTOR, 2010).

Nesta perspectiva, Bezerra e Schneider (2012) ressaltam que a dinâmica do sistema agroalimentar hegemônico, incidi no modelo de produção e consumo, trazendo consigo riscos e prejuízos importantes, tanto no que se refere à saúde e qualidade dos alimentos, considerando os 
aspectos de redução de nutrientes e contaminação por agrotóxicos, como na dimensão social e cultural da alimentação, ocasionando uma profunda redução do consumo de alimentos, culturalmente utilizados e produzidos local e/ou regionalmente, descaracterizando, assim, o consumo típico-tradicional de um povo.

Ploeg (2008, p.22) salienta que a industrialização representa, em primeiro lugar, uma desconexão definitiva entre a produção e consumo de alimentos [...] também, coincide com um controle 'imperial' direto e crescente sobre a produção e consumo de alimentos". Por consequência, os espaços de produção e consumo se distanciam, de modo que a produção de alimentos industrializados se fortaleça, suscitando a "superimposição" (p.41) da indústria que, por sua vez, impõem à sociedade preterir os alimentos in natura ou de produção artesanal (BEZERRA; SCHNEIDER, 2012). Além disto, estes processos que afetam a diversidade alimentar lesionam o direito de cada pessoa, ou grupo, exercer a livre escolha sobre o que consumir e também produzir (BRAGA, 2004).

Concomitante a esta dinâmica, Amorozzo (2002) evidencia que os quintais produtivos oportunizam a diversidade alimentar, assim como a preservação da cultura alimentar e dos recursos naturais, por suprirem e suplementarem, mesmo que em parte, as necessidades de subsistência diárias, na maioria dos domicílios, colaborando para melhoria da qualidade alimentar das famílias. As pequenas produções vegetais desenvolvidas nos quintais domésticos permitem às famílias, além de uma melhor alimentação, acesso a frutas, hortaliças, especiarias e plantas medicinais.

Para fins de entendimento, os quintais produtivos são considerados como um sistema de produção de diversas espécies (CARNEIRO, et al. 2013), constituído pelo espaço de terra situado próximo a residência, tornando-o de fácil acesso (BRITO; COELHO, 2000). Nestes podem existir a combinação de árvores, arbustos, trepadeiras, herbáceas, hortaliças e plantas medicinais, algumas vezes em associação com a criação de animais, crescendo adjacentes à residência (NAIR, 1993).

A produção para autoconsumo é praticada não apenas por famílias residentes em áreas rurais, mas também por um grande número daquelas situadas em áreas urbanas e periurbanas, como uma estratégia de ampliar o acesso familiar à alimentação ou parte dela (GADELHA; MALUF, 2008).

Diversos autores têm relacionado à melhoria da situação de Insegurança Alimentar e Nutricional (ISAN) de famílias, cujos domicílios contam com a presença de quintais produtivos (AMBRÓSIO; PERES; SALGADO, 1998; MONTEIRO; MENDONÇA, 2004; LACERDA, 2008). 
De acordo com a Escala Brasileira de Insegurança Alimentar (EBIA), domicílios classificados com Segurança Alimentar são aqueles cujos moradores têm acesso regular e permanente a alimentos de qualidade e em quantidades adequadas, sem prejudicar o acesso a outras necessidades essenciais. No caso dos domicílios onde há presença de algum grau de ISAN, percebese, no caso da manifestação leve, alguma preocupação com o acesso aos alimentos e um comprometimento em relação à qualidade acessada. Nos domicílios com ISAN moderada, os moradores adultos convivem com a restrição quantitativa de alimentos e, nos domicílios com ISAN grave, tanto os adultos como as crianças apresentam privação alimentar (SEGALL-CORREAA; MARIN-LEON, 2009).

As causas da ISAN, de parte significativa da população brasileira, estão relacionadas, diretamente, às dificuldades de acesso aos alimentos, seja pelo não acesso aos meios produtivos ou por falta de trabalho e renda, necessários para a aquisição dos alimentos (GADELHA; MALUF, 2008).

Neste sentido, o trabalho visa refletir e debater sobre as possíveis contribuições da presença de hortas caseiras, e o todo do quintal produtivo, na situação de Segurança Alimentar e Nutricional das famílias, buscando compreender a percepção dessas famílias, no que se refere à contribuição dos quintais produtivos na própria alimentação.

\section{Metodologia}

Ressalta-se que este trabalho, desenvolvido na Residência Multiprofissional em Saúde da Família, foi parte integrante do projeto de pesquisa, intitulado "Quintais Produtivos e sua relação com a Segurança Alimentar e Nutricional", vinculado ao Departamento de Nutrição da Universidade Federal do Paraná. O projeto foi aprovado pelo Comitê de Ética em Pesquisa, sob registro número: 42743415.0.0000.0102.

Tratou-se de uma pesquisa de campo, exploratória, de abordagem quantiqualitativa. Conforme salientado por Minayo (2004), o conjunto de dados quantitativos e qualitativos não se opõe, uma vez que estes se complementam, já que os dados objetivos e subjetivos trazem dimensões distintas e ênfases diferentes, o que justamente atribui valor nesta integração.

No decorrer desta pesquisa, um dos métodos utilizados foi a observação participante, mediante uso de diário de campo, para obtenção de informações adicionais. Assim como, uso de 
gravador portátil e registros fotográficos, ambos com o consentimento de cada participante. Cruz Neto (2004) salienta que o diário de campo possibilita a observação direta da realidade do participante, obtendo assim uma variedade de situações ou fenômenos que não são apenas expressas em respostas.

A presente pesquisa foi desenvolvida entre maio de 2015 e janeiro de 2016, no município de Colombo/Paraná, nas áreas de abrangência: 135, 136 e 137, da Unidade de Saúde da Família (USF) Liberdade, denominadas, respectivamente de: Área1 $\left(\mathrm{A}_{1}\right)$; Área2 $\left(\mathrm{A}_{2}\right)$; Área3 $\left(\mathrm{A}_{3}\right)$.

Os sujeitos que compuseram esta pesquisa correspondiam a uma parcela de indivíduos, de ambos os sexos, maiores de 18 anos, participantes de reuniões mensais de um Grupo da USF Liberdade. A seleção dos participantes foi realizada entre os meses de julho e agosto de 2015, durante tais reuniões, sendo convidadas a participar da pesquisa as pessoas que relataram possuir quintal produtivo em seu domicilio. A participação ocorreu de forma voluntária, após assinatura do Termo de Consentimento Livre e Esclarecido (TCLE).

A coleta de informações ocorreu por meio de três etapas: 1) Aplicação da Escala Brasileira de Insegurança Alimentar (EBIA); 2) Entrevista semiestruturada e 3) Caracterização dos quintais produtivos.

Na Primeira Etapa, houve a aplicação da EBIA, a qual mede diretamente a percepção e vivência de insegurança alimentar e fome no nível domiciliar, sendo uma medida capaz de mensurar a dificuldade de acesso familiar aos alimentos e também parte das dimensões psicológicas e sociais da insegurança alimentar (MDS, 2014). De acordo com Kepple e Segall-Corrêa (2011) esta escala aplicada isoladamente, não é adequada para medir a complexidade de um fenômeno multidimensional e interdisciplinar como a SAN, que abarca uma multiplicidade de aspectos.

A Segunda e a Terceira etapa ocorreram no domicílio dos participantes da pesquisa.

Para a Segunda Etapa utilizou-se a entrevista semiestruturada, norteada por um roteiro de perguntas sobre o perfil socioeconômico e as percepções dos participantes acerca de seus quintais produtivos. A estruturação deste roteiro contemplou as recomendações de Manzini (2003) e Toloi e Manzini (2013), no que tangia a análise e ao processo de realização.

Inicialmente as entrevistas semiestruturadas destinavam-se a coletar informações do participante, porém em alguns momentos, houve colaboração de um ou mais membros da família, nas respostas, sendo assim considerados também como sujeitos da pesquisa. Em virtude disto, e de modo a assegurar o anonimato dos participantes, a classificação das falas foi subdividida em dois 
grupos: Entrevista Individual (EI) e Entrevista Familiar (EF), seguida por uma identificação numérica, conforme ordem de ocorrência das entrevistas.

Algumas respostas da entrevista semiestruturada foram categorizadas por meio da Análise de Conteúdo. Este procedimento de análise abrange um conjunto de técnicas de organização das informações, que utiliza procedimentos sistemáticos e visa compreender o sentido das comunicações (BARDIN, 2002). A formação das categorias foi realizada a partir da análise de tópicos emergente nas unidades temáticas, configurada de acordo com critérios de frequência e relevância.

Para análise e interpretação da produção de sentidos foi utilizada a abordagem francesa da Análise de Discurso, adotada como referencial teórico e metodológico. A Análise de Discurso (AD) possibilita captar os sentidos que o sujeito manifesta por meio do seu discurso, embasado em uma interligação entre a linguagem com o social, a história, e a ideologia. Neste sentido, a AD vai além do texto, trazendo sentidos pré-construídos que são ecos da memória coletiva, construída socialmente (ORLANDI, 2009).

Durante a Terceira Etapa, os quintais produtivos foram caracterizados, a partir de registros fotográficos e de anotações, em diário de campo, dos relatos acerca das variedades de animais e plantas existentes, seus usos e técnicas de manejo.

A princípio, nesta etapa, buscou-se identificar os alimentos de origem animal e vegetal, de fins culinários e medicinais, todavia, desde a realização da primeira entrevista, percebeu-se a necessidade de considerar também relevante como parte deste levantamento as Plantas Alimentícias Não Convencionais (PANCS).

Para classificação das variedades, presente nos quintais produtivos, optou-se pela listagem e descrição das espécies, considerando os nomes populares indicados, em sua maioria, pelos entrevistados, e outros por consulta a agentes comunitárias de saúde (ACS) e pesquisa em literatura especializada (KINUPP; LORENZI, 2014).

Para apresentação dos dados as variedades de uso alimentar indicadas pelos entrevistados foram separadas por grupos de alimentos, adaptado de Ornellas, (2007), a saber: Frutas, Condimentos e Hortaliças (cereais, folhas, flores, frutos, leguminosas, tubérculos e raízes), bem como dois outros grupos: Plantas Medicinais e Plantas Alimentícias Não Convencionais. Para agrupamento da presença e da frequência das plantas encontradas, por grupo, utilizou-se a representação gráfica de mineração de texto - Nuvem de palavras. A interpretação da representação 
gráfica ocorre conforme o tamanho da palavra na nuvem, quanto maior o tamanho, maior a frequência da planta nos quintais produtivos estudados.

A delimitação da suficiência das informações foi realizada a partir do critério de saturação, sendo a coleta entendida como satisfatória e finalizada, quando da repetição de informações (VICTORA; KNAUTH; HASSEN, 2000).

\section{Resultados e discussões}

O universo desta pesquisa se constituiu de um total de 18 entrevistas semiestruturadas, sendo seis entrevistados de cada uma das áreas de abrangência da USF. O conjunto de participantes das entrevistas foi de 23 indivíduos, destes 5 eram do sexo masculino e 18 do sexo feminino, a maioria (17) possuía idade igual ou acima de 50 anos. Este número de entrevistados, superior ao número de entrevistas realizadas (18), refere-se ao fato de terem ocorrido colaborações de familiares, conforme detalhado na metodologia. Observou-se que, o número de moradores por domicílio variou de 1 a 4, totalizando 55 pessoas nos 18 domicílios investigados, sendo 49 adultos e 6 menores de 18 anos.

A existência dos quintais produtivos está associada ao tempo de moradia dos participantes nos domicílios. Este tempo se expressa como uma variável que pode indicar a relação dos entrevistados com o local onde vivem e com a prática de cultivo no ambiente urbano. Observou-se que quanto maior o tempo de moradia no domicílio, maior era o tempo de existência dos quintais. Neste caso, o tempo de existência variou de 1 a 23 anos, sendo que parte significativa (9) possuía quintais há mais de 10 anos. Segundo Moser (1998), a dimensão temporal e a noção de história são essenciais para esclarecer como o indivíduo constrói uma identidade residencial, com base em sua história residencial, que influenciará sua percepção e avaliação de seu domicílio atual.

A situação de saneamento básico está relacionada a uma das dimensões de análise da segurança alimentar nutricional, visto que pode implicar no aparecimento de doenças relacionadas à carências nutricionais, tais como anemia e desnutrição, agravando a situação de saúde (OLIVEIRA et al., 2015). No que tange a situação de saneamento básico, os serviços fornecidos às famílias participantes desta pesquisa, em geral, apresentavam boas condições, pois todas as residências possuíam esgoto encanado, destinação correta do lixo, e a maioria (17) contava com água tratada da SANEPAR, sendo que apenas uma não possuía água encanada, a qual era proveniente de poço 
artesiano. De acordo com, os dados apresentados, em 2013, no Plano Municipal de Saúde 20142017, o município teria 45,42\% de atendimento de esgoto, e $100 \%$ de cobertura residencial urbana de abastecimento de água (COLOMBO, 2013). Entretanto percebe-se há um contraste entre esta informação, sobre o índice de cobertura, com o evidenciado nesta pesquisa.

Em relação ao cuidado do quintal, na maioria (11), as mulheres foram as principais responsáveis pelo manejo destes ambientes e desenvolvimento das atividades. Nos demais, 3 estavam sob a responsabilidade do homem, e 4 sob a responsabilidade compartilhada.

Vários estudos (FREITAS, 2012; OLIVEIRA, 2009; SABBATO et al., 2009) destacam que, a maioria das experiências em quintais produtivos tem em comum o protagonismo de mulheres. Conforme salientado por House \& Ochoa (1998), as mulheres geralmente têm uma percepção multidimensional, e buscam ampliar a biodiversidade de cultivos, contribuindo para uma produção diversificada. As experiências desenvolvidas pelas mulheres na produção de alimentos e plantas medicinais, em quintais produtivos, têm tido papel crucial nos cuidados com a segurança alimentar, na valorização da produção para autoconsumo, no resgate da cultura alimentar e de cultivos alimentares locais (valorização de alimentos regionais), e na relação entre saúde e consumo de alimentos sadios, livre de agrotóxicos e transgênicos (RIGON et al., 2010).

Visto que titulares de direito de programas de transferência de renda, como o Bolsa Família, apresentam condições de maior vulnerabilidade, estando mais suscetíveis aos determinantes da ISAN (MEDEIROS, 2015), investigou-se este indicador entre as famílias. No entanto, apenas duas famílias referiram que tinham acesso a este programa, sendo que em uma delas ocorreu presença de ISAN Leve, segundo a EBIA. Outro fator interessante, é que nenhuma das famílias recebia doação de alimentos, ao contrário, a maioria (12) referiu praticar doação de alimentos não perecíveis, não provenientes dos quintais.

Acerca do destino dado as plantas provenientes dos quintais produtivos, praticamente todos os participantes (17), além de relatarem o autoconsumo, também faziam doações das mesmas. Esta prática reflete aspectos importantes dos quintais, como, o potencial de socialização e resgate cultural de relação com o ambiente, plantas e pessoas.

Para os sujeitos desta pesquisa, os quintais produtivos assumem a função de fonte de alimentos diversificados, visto que a maioria (11) tinha uma utilização diária, ou pelo menos três vezes na semana (5), dos alimentos para autoconsumo e/ou uso medicinal, proporcionando acesso a uma maior gama de itens alimentares e contribuindo para SAN das famílias. 
Os quintais produtivos desempenham funções essenciais de natureza econômica, social, nutricional, cultural e ambiental, que se destacam na reprodução da vida familiar.

Destaca-se que a situação do imóvel em paralelo à estruturação familiar, de alguns entrevistados (10), foi relatada como impedimento para o cultivo nos quintais e/ou sua manutenção. De modo geral, as famílias que residiam em casas, nas quais se compartilhava e/ou pretendia-se compartilhar o espaço para moradia de parentes, a área de cultivo era restrita. Este quadro é similar ao apontado por Amorim, Carvalho e Barros (2015), em que existe uma crescente necessidade de maximizar o uso dos domicílios nos centros urbanos com aproveitamento total do lote, implicando na diminuição e/ou extinção das áreas abertas do domicílio, incluindo o quintal.

\section{Produção de sentidos sobre os quintais produtivos}

Em relação à análise de conteúdo, foram estruturadas duas Unidades Temáticas, definidas com base no corpus do trabalho.

Unidade Temática 1. Significado dos quintais produtivos, com a configuração de quatro categorias:

Na Categoria 1.1 Promoção de Saúde, os elementos que predominaram, em todas as percepções (18), caracterizavam a manutenção do quintal produtivo a valores relacionados ao prazer de cultivar, espaço de lazer, bem-estar, promoção de saúde e autonomia no cuidado, como pode ser observado nos depoimentos, a seguir:

Eu adoro ter, eu gosto, eu acho tão bonito. Eu tenho que comer quase tudo natural (...) Nós que temos pressão alta, temo diabetes, temo colesterol alto, ai é bom ter coisa assim, do quintal. (EF1)

Acho que é uma distração pra mim. Distrai os nervos da gente quando tá na horta (...) $($ EI5)

Pra mim eu acho tudo. Por que eu tomo no chimarrão, faço chás, faço chá se tiver com dor de estômago, faço chás pras crianças, xaropinho (fala com sorriso no rosto) (...) (EI6)

Dá diferença na saúde (...)(...) pelo fato de você tá lá, limpando, carpindo, cuidando, já tá se exercitando e de pega aquilo lá bem saudável. (EI9)

Partes das assimilações acima correspondem aos contextos de saúde que os participantes estavam inseridos, os quais compreendiam o consumo dos alimentos provenientes do quintal como 
condutor a estilos de vida mais saudáveis, havendo uma ligação entre cuidado da saúde, em parte, de forma autônoma, com o consumo dos alimentos do quintal. Outros aspectos vinculados à saúde e bem-estar, envolviam o sentido de que a ocupação com o quintal se configurava a uma forma de exercício físico, distração e prazer.

Considerou-se como relevante, para análise a categoria 1.2 Promove consciência ambiental, mesmo que apenas um participante a tenha mencionado.

Essa questão também do uso de matéria orgânica, que a gente usa, que nem aqui em casa o nosso lixo, é aquele lixo mesmo que não tem jeito, mas casca de laranja ela serve de adubo ali na horta, pro quintal, para um vaso de planta, não é jogado no lixo pra ir pro aterro. (EF3)

Destaca-se que as inter-relações entre os seres humanos, natureza e trabalho, de acordo com Grisa (2007) os mantém conectados em forma de coprodução, uma vez que priorizam a utilização dos recursos materiais e sociais disponíveis localmente de forma sustentável, preservando a natureza, em razão de, ao mesmo tempo, permitir sua reprodução, garantindo a existência de ciclos futuros e uma base de recursos autocontrolada.

Os significados, abordados por nove entrevistados, contidos na categoria 1.3 Confere sentido de existência, ser e estar, são complementares aos apresentados na primeira categoria, como pode ser percebido em alguns exemplos:

(...) se a gente tem alguma coisa pra planta a gente tem alguma coisa pra cuidar. (...) Pra mim é uma terapia. Pra gente ter alguma coisa pra fazer, pra não ficar assim parado. (EI3)

Pra mim é tudo (sorri), às vezes eu to aqui sozinha, ando, pego a faca, vou lá já começo a cutucar, me distrai. (EI4)

(...) é a minha riqueza na vida, meu passatempo, é minhas planta aqui, até dentro de casa, tudo é a minha vida. Acho que se não tivesse essas plantas eu já tinha morrido de solidão aqui. (EI10)

Nota-se que os entrevistados conferiam ao quintal produtivo um significado estendido, no qual este assume elementos afetivos, assim como uma função de elevação da autoestima, pois o trabalho diário dedicado à produção do próprio alimento e/ou manejo do ambiente, ajuda a criar a consciência das atividades habituais e do sentimento de identificação, plenitude e satisfação.

Os resultados apresentados em pesquisa realizada por Mendonça e Lunardi (2003), acerca das motivações e interesse para manutenção dos quintais produtivos, assemelham-se aos 
apresentados neste trabalho, já que algumas das evidências apontadas pelos participantes também foram: alimentação (disponibilidade e qualidade do alimento e sua interferência na saúde) e ocupação, referindo-se ao prazer/gosto de plantar e ao cultivo como forma de ocupação e terapia.

Parte desta perspectiva provavelmente estava relacionada aos aspectos de ocupação para obtenção de renda, visto que a maioria dos moradores (15) possuía trabalho informal (sem carteira assinada), assim como uma parte significativa (14) era aposentada, destes dois também eram pensionistas. Alguns (9) tinham trabalho formal, outros (5) eram Do Lar, (1) pensionista, (3) desempregados e (2) recebiam benefício (auxílio doença). Portanto, a maioria dos moradores, e principalmente aqueles que mais se envolviam no cuidado do quintal, dispunham de uma maior parcela de tempo para esta prática, valorizando o quintal produtivo como meio de ocupação e lazer.

Nos depoimentos da categoria 1.4 Remete à origem, a maioria dos entrevistados declarou ter obtido os conhecimentos da prática de cultivo de alimentos e manejo do quintal na própria família. Notou-se uma relevância dada à tradição, valores, costumes e hábitos rurais, caracterizando a existência de uma herança cultural no repasse de saberes, assim como no estudo de Mendonça e Lunardi (2003), a qual seria transmitida por meio de pais e avós, que passaria a ser assimilada e carregada como herança.

(...) eu e ela, a gente já tinha um hábito, desde morar na roça, e a gente foi vendo, que hoje as hortaliças, principalmente os produtos que a gente tem hoje ai na horta, eu acho que é muito importante, pra nós dois. (EF3)

Porque toda vida a gente morou no sítio, a gente comia todas as coisas tudo plantado (...) (EI8)

Desde pequena, porque lá na roça a gente mexia com terra, ia pra roça, plantar feijão (...) (EI13)

Verificou-se que os depoimentos acima estão relacionados à origem dos entrevistados, visto que, nenhum deles era natural do município de Colombo, mas eram provenientes da área rural, sobretudo do Paraná, mas também de outros estados, como: Rio Grande do Sul, Santa Catarina, Minas Gerais, Bahia, bem como de outro país, no caso do Paraguai (uma entrevistada). Em razão desta realidade, a maioria dos entrevistados relatou possuir alguma relação com o ambiente rural, por terem sido criados em áreas rurais e auxiliarem desde a infância em atividades deste meio e apreendido de geração em geração, às práticas agrícolas. Esta conjuntura é semelhante à evidenciada por Amorozo (2002), o qual destacou que o cultivo em comunidades rurais tradicionais é algo que se aprende muito cedo, à medida que as crianças acompanham os adultos às roças. 
Talvez por este fato, alguns participantes tenham referido, estes acontecimentos como limitantes para o avanço escolar, como pode ser observado nas falas a seguir:

Eu tirei o primeiro ano, quando entrei pro segundo, meu pai me tirou. Me tirou da escola, pra cuidar da casa e das criações, pra eles poderem ir trabalhar. (EI 8)

Eu nunca estudei, meu estudo foi à roça. Eu ajudava na roça direto, desde os sete anos. Nós não podia com a inchada, nós ia arrancando o mato, debaixo daquelas coivara, de pau que fazia derrubada, onde a inchada não ia nossas mãos ia. Limpava cova de café, aquele frio, cinco horas da manhã, nós tava tudo na roça, ficava só a mãe na casa. E ainda nós socava o arroz no pilão, nós tinha dó da mãe, que cozinhava pra um monte de criançada, e então nós socava o arroz pra ela de noite. (EI 10)

De modo geral, em consequência a este histórico, os entrevistados apresentaram baixa escolaridade, dado que 5 nunca frequentaram a escola, não sendo alfabetizados, 12 não completaram o ensino fundamental, e apenas 1 referiu ter primeiro grau completo.

Neste sentido, segundo Medeiros (2015) indivíduos cujos níveis de escolaridade são baixos, consequentemente apresentam falta de qualificação profissional, o que pode resultar em menor renda, como no caso dos participantes desta pesquisa, tornando-os mais suscetíveis às dimensões de vulnerabilidade e insegurança alimentar.

Em relação à Unidade Temática 2. Alimentos dos quintais produtivos, três categorias foram identificadas:

A categoria 2.1 Garante acesso aos alimentos, reflete percepções que conectam a existência do quintal produtivo à oportunidade de acesso simplificado aos alimentos. Os relatos pertencentes a esta categoria (15) corroboram com Harwood (1986), o qual salienta o fato da diversidade de cultivos presentes nos quintais romper com a monotonia da dieta das famílias, principalmente daquelas mais vulneráveis economicamente, por aumentar a variedade e a frequência dos alimentos consumidos. Esta assertiva fica evidente nas falas expostas a seguir, e na observação do Quadro 1 e da Figura 1, apresentados após as discussões das percepções.

Isso que eu falei pra você, você nunca vai dizer "ah hoje eu não tinha o que comer", nunca!(EI9)

É tudo mais próximo da gente também né. Porque às vezes a gente fica com preguiça de ir lá no mercado comprar, e tá tudo ali na horta. (EF3)

(...) o maracujá do mercado é meio seco, e dai de certo que o maracujá gosta da terra meio úmida, é cheinho o maracujá daqui, cheinho. Então compensa ter, porque rende mais e o do mercado é sempre falhado. (EI5) 
Associada a esta categoria verificou-se que, para a maioria das famílias participantes (14), as funções econômicas dos quintais produtivos, transcendiam o valor econômico que poderia estar vinculado à condição de acesso alimentar. Uma vez que incorporavam um valor simbólico a estes, por caracterizá-los como uma fonte de renda não monetária, correspondente a um melhor rendimento dos alimentos oriundos dos quintais produtivos e ao valor economizado por meio de seu consumo.

Percebeu-se que a conexão exposta nesta categoria, traz elementos que exploram a noção de proximidade entre produção e consumo, mediante acesso direto para alimentação. Compreendeu-se que esta noção poderia ter sido construída ao longo das histórias de vida e vinculada a origem dos entrevistados, visto que existem regiões do interior, onde se criam dinâmicas alimentares autônomas da lógica mercadológica, como a produção para autoconsumo, devido à logística, uma vez que os comércios são distantes dos domicílios.

Os depoimentos desta categoria demonstram como o quintal produtivo, para as famílias participantes, pode exercer um papel gerador de economia e tornar-se uma alternativa de acesso alimentar, mesmo dentro de uma realidade em que seus domicílios estão próximos a comércios, delineando certa independência frente à imposição mercadológica da compra de alimentos. Percebeu-se, em alguns domicílios (3), certa vulnerabilidade econômica realçada, principalmente, pelo fato de nenhum morador possuir renda fixa. Tal situação gera instabilidade, dificultando a realização de previsões com gastos indispensáveis, como alimentação, ocasionando em certas vezes incertezas, como discutido por Albuquerque e Nava (2012). Fato que pode estar associado à presença de ISAN Leve em duas destas famílias.

Ainda que a disponibilidade de orçamento represente uma variável determinante para obtenção da SAN, Bezerra (2010) salienta que a compreensão desta não se restringe apenas a condição econômica, uma vez que a satisfação das necessidades alimentares contempla uma complexa teia de relações sociais, econômicas e culturais.

A presença de segurança alimentar e nutricional em um dos domicílios, referidos acima corrobora com o destacado pela autora supracitada. Do mesmo modo que, a existência de renda fixa em algumas famílias (15) não garante a manifestação exclusiva de SAN, uma vez que, embora dez destas famílias tenham manifestado SAN, o restante apresentou algum grau de Insegurança Alimentar, sendo que quatro convivem com ISAN Leve, e uma com ISAN Moderada, de acordo com o resultado obtido pela EBIA. 
Tendo em vista que, o conceito de SAN também abarca as questões relacionadas ao não comprometimento do acesso a necessidades essenciais, a falta de imóvel próprio, bem como os custos relacionados à melhoria nas moradias podem comprometer a situação de SAN, conforme exposto por Medeiros (2015). Observou-se que, em relação à situação do domicílio, se próprio ou não, a maior parte (17) das famílias possuía domicilio próprio, destas 3 ainda estavam pagando o imóvel, 4 não tinham documentação e 1 possuía casa cedida por familiar. Considera-se que este aspecto pode ser um dos que contempla a teia de relações mencionada anteriormente e pode estar associado com a presença predominante de famílias com SAN.

Tendo em consideração as informações sobre a percepção dos rendimentos totais na manutenção e reprodução familiar, evidenciou-se que, a predominância de famílias que possuíam domicílio próprio e algum morador com renda fixa, exposta anteriormente, pode estar vinculada ao fato da maioria participante (17) não expressar preocupação significativa quanto à disponibilidade do orçamento familiar, dado que, 9 destes afirmaram passar o mês com facilidade, 8 com alguma facilidade e apenas 1 com dificuldade.

De acordo com a categoria 2.2 Oferece alimentos naturais e saudáveis, a maioria (17) dos depoimentos, incluía a reflexão da não utilização de agrotóxicos e/ou substâncias química, no que era cultivado nos quintais produtivos, caracterizadas como veneno, e consequentemente prejudiciais à saúde, quando comparados aos alimentos adquiridos nos mercados. Desta forma, existia uma convicção de que a parcela dos alimentos consumidos dos quintais produtivos era isenta de veneno, o que proporcionava uma despreocupação e segurança quanto ao que se consumia, como observado nas seguintes falas:

O que vem de fora tem tudo quanto é tipo de defensivo agrícola. Esse tipo de veneno que eles usam. (...) Tanto legume como verdura, eles usam um tipo de adubo, que elas (...) crescem mais rápido, então aquele crescimento tira um pouco do gosto. (...) ter alguma verdura que não foi usado algum tipo de veneno, a gente ter assim no quintal, nossa. A gente sabe o que tá colocando no prato. (EF4)

Claro que é diferente que o meu aqui não tem veneno e o de lá tem né. Eu acho que é mais sadio pra gente, porque quando a gente traz as verduras do mercado, parece que é...sei lá.... gente tem que ponha de molho, com um pouquinho de vinagre, pra poder cortar um pouco o veneno. Porque eu sei que tem veneno, por que aqui a gente não passa, mas lá fora pra ficar bonita né, eles passam veneno. (EI10)

Toda vida. Com certeza, a minha é melhor, mais gostosa, mais saudável. Acho que é porque não tem adubo, não tem veneno, nada, é mais saudável (...) (EI12) 
A maioria das famílias (14) tinha o controle da procedência e da qualidade do que era produzido, já que, não utilizavam substâncias químicas nos quintais, havendo predomínio de práticas de manejo semelhantes às agroecológicas, como compostagem e outras técnicas de adubação da terra, priorizando o aproveitamento de recursos locais, assim como controle ecológico de vetores.

A agricultura urbana de base ecológica, praticada nos quintais produtivos, maximiza o controle biológico natural de pragas e doenças, desenvolvendo um processo de autorregulação. De maneira oposta, o uso de agrotóxicos e/ou adubos químicos, tendem a descontrolar todo o sistema biológico, tornando as plantas vulneráveis ao ataque das pragas, rompendo com o equilíbrio ecológico e degradando a natureza (MUTUANDO, 2005). Nesta lógica, os depoimentos desta categoria também enfatizavam a atribuição de qualidade sensorial superior aos alimentos que eram provenientes dos quintais produtivos, caracterizando os existentes nos mercados como inferiores, os quais se encaixam dentro de uma lógica de produção acelerada, que não respeita o crescimento e desenvolvimento natural das plantas e/ou animais, estando distanciada do consumidor.

Destacou-se na fala EF4, o termo defensivo agrícola, que pode estar relacionado ao fato dos entrevistados terem crescido e vivido em meio rural, no contexto de uma época, de acordo com Pacheco (2013), em que havia incentivo ao uso de agrotóxicos. Durante a "Revolução Verde", por volta da década de 70, cunhou-se e assimilou-se na sociedade, a utilização da expressão "defensivo agrícola”, que se perdura até os dias atuais. Segundo a Nota Técnica de esclarecimento, da Agência Nacional de Vigilância Sanitária (ANVISA) (2016), sobre o risco de consumo de frutas e hortaliças cultivadas com agrotóxicos, existem muita desinformação em relação a esta questão, como exemplificado na fala da EI10, que acredita que a utilização destas substâncias seria capaz de deixar os alimentos mais bonitos, existindo uma forma de remover e/ou eliminar a quantidade presente nos alimentos.

Entretanto o uso de substâncias químicas está diretamente relacionado à segurança alimentar, visto que a segurança dos alimentos está contemplada no contexto de SAN. Deste modo, a não utilização de fertilizantes químicos e agrotóxicos na produção de alimentos representa fator chave na garantia do alimento saudável e de qualidade às famílias, isto tanto em relação aos alimentos comprados nos mercados como provenientes dos quintais produtivos.

Destaca-se neste estudo, que os alimentos produzidos em quintais produtivos urbanos, assim como evidenciado por Ricarte-Covarrubias, Ferraz e Borges (2011), em duas comunidades de São Paulo, geralmente têm se mostrado livres ou em uso limitado de agrotóxicos e herbicidas. 
Evidenciou-se que uma minoria de famílias (4) fazia uso de agrotóxicos e/ou adubos químicos em seus quintais. Fazendo uma relação desta utilização com a situação de segurança alimentar, apenas uma destas famílias apresentava ISAN leve, conforme a EBIA, entretanto, cabe aqui salientar que esta classificação se torna questionável, quando se leva em conta o conceito amplo de segurança alimentar e nutricional, discutido nesta pesquisa.

Nesta perspectiva, Azevedo e Ribas (2016) trazem uma reflexão crítica sobre as limitações da EBIA em apontar e abarcar as complementaridades entre a vivência da ISAN e os processos e agentes de produção deste fenômeno, na medida em que não inclui elementos estruturais que classificam os indivíduos em situação de insegurança, isto é, não indica o desequilíbrio e a erosão cultural da dieta e dos sistemas alimentares ou a contaminação química e genética dos alimentos como elementos de insegurança.

Alguns participantes (EI3, EI5, EI11, EI14), em nenhum momento apresentaram as percepções contidas nesta categoria. Compreendeu-se que isto pode ter ocorrido em razão de que estas famílias utilizavam veneno e/ou adubo químico nos quintais produtivos, como foi relatado durante a entrevista semiestruturada e constatado pela observação participante, principalmente em laranjeiras, pessegueiros e couves. Notou-se que estas pessoas valorizavam seus quintais devido a outras contribuições que estes poderiam gerar, não considerando muitas vezes sua alimentação proveniente do quintal como diferenciada da convencional, estabelecendo um reforço do modelo hegemônico de produção e consumo de alimentos. Nestes casos, percebeu-se que as pessoas que utilizavam estes venenos não conseguiam reconhecê-los como prejudiciais à saúde.

A categoria 2.3 Favorece Partilha, foi analisada devido ao critério de relevância. A fala que agrega esta percepção é exposta a seguir: "Faz tempo, eu servia tudo os vizinho de verdura, desde $2001 "$ (EF2).

Redes de trocas entre vizinhos e parentes vem sendo expostas, mediante levantamentos, realizados em quintais urbanos e rurais, registrando a relevância dos sistemas informais de troca de conhecimentos e de recursos tradicionais (AMARAL; GUAMIRIM NETO, 2008; WINKLERPRINS; OLIVEIRA, 2010; SIVIERO et al. 2012).

Neste sentido, em meio a toda conjuntura das percepções apresentadas, entrelaça-se aqui um paralelo ao destacado por Khatounian (2001), em seu livro A reconstrução ecológica da agricultura, sobre a necessidade de uma reeducação alimentar dos consumidores, para que seja possível conjugar abastecimento seguro, boa nutrição humana e preservação dos recursos naturais. 
Com isso, os quintais produtivos, tanto urbanos como rurais, se encaixam no que este autor chama de soluções locais, reforçando a percepção de pensar global e agir local.

Houveram percepções que não se encaixaram em nenhuma das duas Unidades Temáticas discutidas anteriormente. Visto que alguns entrevistados (3) pareciam não conseguir vislumbrar uma associação entre o quintal produtivo e a alimentação e, outros (3) não considerarem o quintal como um fator contribuinte na renda, como notado abaixo:

Eu compro bastante também, porque ali é muito pequeno, não dá pra plantar tudo o que a gente quer, aí eu compro alface, repolho, porque ali é pequeno não dá pra enche também. (EI4)

Mas lógico que a gente tem de tá comprando, porque a gente nunca tem de tudo no quintal (riso). Que nem hoje eu cozinhei brócolis, couve-flor, e esse aí a gente não tem, a terra não produz, não tem espaço. (EI7)

(...) por que não muda nada pra gente. Por que a gente compra a fruta e a verdura. (EF2)

Se faz diferença na renda.. Acho que não (enfatizado). (EI3)

Os dois primeiros depoimentos enfatizam a dependência alimentar que existia em suas famílias ao mercado, referindo espaço insuficiente no quintal e não produção do que se deseja.

$\mathrm{Na}$ fala da EF2, nota-se que o não estabelecimento de contribuição, pode estar relacionado à marcante dependência de aquisição dos alimentos. Estas compreensões, também podem ser em razão da forma como estes entrevistados interpretaram a pergunta, elaborando respostas a partir de uma reflexão sobre acréscimo à renda e não no sentido de economia. Desta forma, possivelmente passariam a considerar alguma interferência no caso de comercialização dos alimentos, o que não se encaixa em nenhuma das realidades pesquisadas.

\section{Caracterização dos quintais produtivos}

Obteve-se como resultado da caracterização dos quintais produtivos, a distribuição das variedades, por família entrevistada e por grupos alimentares, cultivadas nos quintais produtivos urbanos estudados, apresentada no Quadro 1. 


\begin{tabular}{|c|c|c|c|c|c|c|c|c|c|c|c|c|c|c|c|c|c|c|}
\hline \multirow{2}{*}{ GRUPOS } & \multicolumn{18}{|c|}{ ENTREVISTAS } \\
\hline & 武 & $\stackrel{\mathbf{v}}{\mathbf{r}}$ & $\stackrel{m}{\underline{c}}$ & 竞 & 司 & 空 & $\stackrel{9}{\mathbf{I}}$ & 咅 & $\frac{n}{\mathbf{x}}$ & 产 & 言 & $\frac{\infty}{\Gamma}$ & $\stackrel{\theta}{\vec{x}}$ & 空 & $\Xi$ & $\stackrel{\Xi}{\mathbf{I}}$ & $\stackrel{3}{\mathbf{I}}$ & 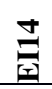 \\
\hline FRUTAS & 4 & $\overline{3}$ & 9 & 2 & $\overline{1}$ & 4 & 2 & $\overline{0}$ & $\overline{15}$ & 1 & 5 & $\overline{6}$ & 14 & 10 & $\overline{6}$ & 10 & $\sqrt{12}$ & 4 \\
\hline \begin{tabular}{|l|} 
LEGUMINOSAS \\
\end{tabular} & 0 & 0 & 0 & 0 & 0 & 0 & 0 & 0 & 0 & 0 & 0 & 0 & 2 & 0 & 0 & 0 & 1 & 2 \\
\hline CEREAIS & 0 & 0 & 0 & 0 & 0 & 0 & 0 & 0 & 1 & 0 & 0 & 0 & 1 & 0 & 0 & 0 & 0 & 0 \\
\hline CONDIMENTOS & 6 & 7 & 5 & 1 & 3 & 6 & 6 & 7 & 12 & 9 & 6 & 6 & 12 & 8 & 8 & 8 & 4 & 7 \\
\hline \begin{tabular}{|l|} 
FOLHAS \\
\end{tabular} & 2 & 1 & 4 & 0 & 3 & 3 & 1 & 1 & 10 & 4 & 4 & 2 & 5 & 6 & 5 & 3 & 3 & 5 \\
\hline \begin{tabular}{|l} 
TUBÉRCULOS E RAÍZES \\
\end{tabular} & 0 & 0 & 1 & 0 & 0 & 1 & 0 & 0 & 0 & 0 & 0 & 0 & 5 & 0 & 4 & 1 & 1 & 2 \\
\hline \begin{tabular}{|l|} 
FRUTOS \\
\end{tabular} & 2 & 0 & 1 & 0 & 0 & 1 & 1 & 0 & 2 & 0 & 3 & 2 & 6 & 2 & 2 & 4 & 3 & 3 \\
\hline FLOR & 0 & 0 & 1 & 0 & 0 & 0 & 0 & 0 & 0 & 0 & 0 & 0 & 0 & 0 & 0 & 0 & 0 & 0 \\
\hline MEDICINAIS & 4 & 2 & 4 & 1 & 3 & 11 & 4 & 6 & 13 & 7 & 10 & 5 & 11 & 5 & 3 & 8 & 3 & 12 \\
\hline OTAL & 18 & 13 & 25 & 4 & 10 & 26 & 14 & 14 & 53 & 21 & 28 & 21 & 56 & 31 & 28 & 34 & 27 & 35 \\
\hline
\end{tabular}

QUADRO 1 - DISTRIBUIÇÃO DAS VARIEDADES POR DOMICÍLIO E POR GRUPOS ALIMENTARES, CULTIVADAS NOS QUINTAIS PRODUTIVOS URBANOS ESTUDADOS. COLOMBO/PR, MAIO DE 2015JANEIRO2016

Fonte: Pesquisa de campo - Quintais produtivos urbanos. Colombo/PR - maio/2015 a janeiro/2016.

Por meio da análise destas informações fica evidente a predominância da diversidade alimentar presente nos quintais estudados. Ainda neste sentido, cinco famílias combinavam a produção de origem vegetal com a criação de animais, sendo predominante o consumo de ovos de galinha. Uma das famílias consumia ovos de gansa e outra tinha o hábito de consumir, além dos ovos, a carne da galinha. Nesta perspectiva, notou-se que havia uma condição estratégica das famílias em manejar a criação animal e vegetal para geração constante de alimento. Esta manutenção dos quintais poderia estar relacionada à compreensão, construída ao longo dos anos, de que conforme seus ciclos de desenvolvimento se criaria um circuito de abastecimento alimentar contínuo.

As variedades de plantas reconhecidas como comestíveis existentes nos quintais limitavam-se a variedades convencionais, salvo algumas plantas alimentícias não convencionais (PANCS) consumidas e apresentadas na Figura 1, como: chicória, taioba, radite, serralha e azedinha. Diversas outras (38) descritas nesta mesma Figura 1, estão presentes nos quintais produtivos, porém não fazem parte da alimentação das famílias. 

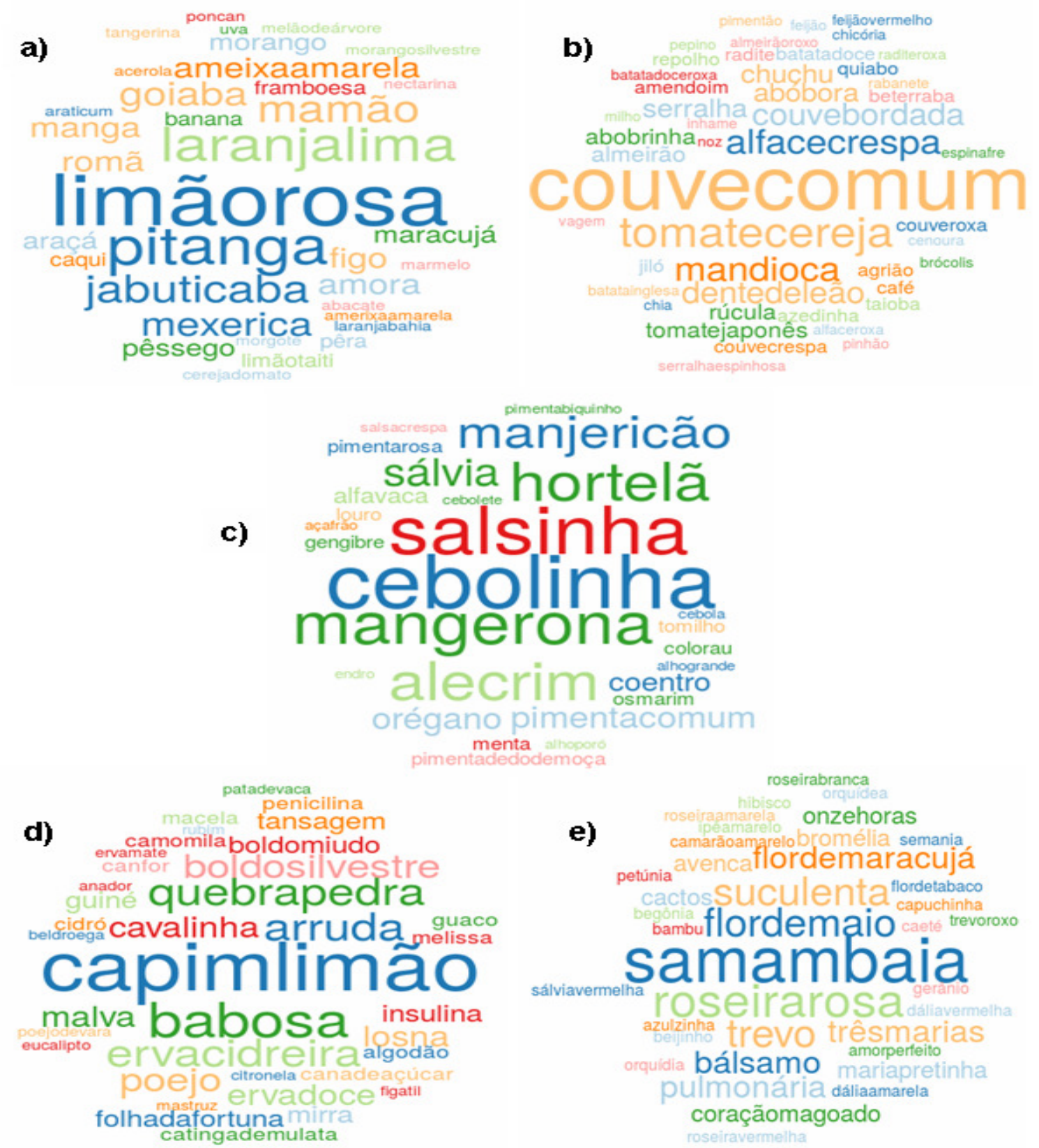

FIGURA 1 - REPRESENTAÇÃO GRÁFICA, POR GRUPOS DE ALIMENTOS, DAS VARIEDADES CULTIVADAS PARA FINS ALIMENTARES E/OU MEDICINAIS. A) FRUTAS. B) HORTALIÇAS. C) CONDIMENTOS. D) PLANTAS MEDICINAIS. E) PLANTAS ALIMENTÍCIAS NÃO CONVENCIONAIS.

Fonte: Pesquisa de campo - Quintais produtivos urbanos. Colombo/PR - maio/2015 a janeiro/2016.

Ainda foram identificadas 11 variedades de plantas, entre flores, folhagens, árvores, e outras plantas, não consideradas até o momento como PANCS, e que não entraram na relação descrita no Quadro 1 e na Figura 1.

Kinupp e Lorenzi (2014) trazem uma importante contribuição ao debate que faz referência as PANCS, plantas espontâneas, que crescem entre plantas cultivadas, sendo por isto, muitas vezes 
inadequadamente chamadas de 'mato', 'daninha' e 'invasoras'. Os autores salientam que apesar de serem desconhecidas, negligenciadas e/ou subutilizadas, por grande parte da população, são espécies indicadoras da condição e qualidade do solo, com grande valor ecológico e alimentício, seja no aspecto de complementar e/ou diversificar a alimentação e, por estarem intrinsicamente ligadas à agroecologia, de sustentabilidade, resiliência, segurança e soberania alimentar.

Cabe aqui destacar que os quintais produtivos, inseridos nesta pesquisa, caracterizavam-se como espaços de produção e acesso a alimentos, fonte de diversos nutrientes, perpassando o sentido dos alimentos que estavam convencionados pelas famílias, ainda que parte das variedades fosse desconhecida e/ou não tivesse valor de mercado, por se tratarem de PANCS.

\section{Conclusões}

Este trabalho revela a capacidade dos quintais produtivos nos espaços urbanos em contribuir com dimensões que transcendem o sentido de saúde ligado apenas a nutrição, por agregar a esta e enaltecer dimensões ampliadas ao bem-estar, prazer, contentamento, plenitude, sociabilidade, identidade e existência, construídas e mantidas pelas relações dos participantes com o espaço em que vivem, no qual o quintal produtivo e os alimentos produzidos são parte integrante.

Salienta-se que a utilização de quintais produtivos urbanos, como os apresentados, apreendida mediante uma herança cultural, configura-se como estratégia para garantir a situação de segurança alimentar e nutricional, tendo o potencial de auxiliar as famílias a melhorarem as suas condições de alimentação e/ou de renda familiar. Outro aspecto relevante desse sistema de produção é ressaltado quando são incorporadas práticas agroecológicas que buscam modelos sustentáveis para geração de alimentos seguros, enriquecendo a alimentação das famílias produtoras, e consequentemente, contribuindo com a garantia da Segurança Alimentar e Nutricional independência em relação à produção e ao consumo de alimentos, preservação da cultura alimentar e produtiva e manutenção da agrobiodiversidade nesses espaços.

Existem várias formas de se ter autossuficiência alimentar, algumas simples e outras mais complexas, em meios urbanos ou longe deles. As experiências expostas neste trabalho destacam, como os quintais produtivos urbanos assumem um papel importante na resistência a constante tentativa do sistema agroalimentar hegemônico em padronizar a produção e consumo de alimentos. Deste modo, os quintais produtivos caracterizam-se por sua riqueza em diversidade de plantas, 
cultivadas e espontâneas, e organismos vivos. Ademais, incitam a reflexão sobre tomadas de decisões para que se estabeleçam novas formas e/ou o resgate de formas milenares de relação com a natureza, com a comida, com o ato de cultivar seu próprio alimento e de se alimentar.

No entendimento de que a situação de SAN depende da garantia de outros direitos para sua consolidação e, na compreensão de que os quintais produtivos podem ser uma via para construção de um espaço dialógico, de socialização e de resgate da autonomia e da autoestima das famílias, ressalta-se a necessidade de ações, projetos, programas e políticas que viabilizem e fortaleçam a existência desta estratégia, visando o empoderamento, a formação cidadã e política e a garantia do Direito Humano à Alimentação Adequada e Saudável, como consequências.

\section{Referências}

AMARAL, C. N.; GUARIM NETO, G. Os quintais como espaços de conservação e cultivo de alimentos: um estudo na cidade de Rosário Oeste (Mato Grosso, Brasil). Boletim do Museu Paraense Emilio Goeldi, v. 3, p.329-341, 2008.

AMBRÓSIO, L. A.; PERES, F. C.; SALGADO, J. M. Diagnóstico da contribuição dos produtos do quintal na alimentação das famílias rurais: Microbacia D'água F., Vera Cruz. Informações Econômicas, São Paulo, v.26, n.7, 1996.

AMORIM, A. N.; CARVALHO, D. B; BARROS, R. F. M. Vinculação afetiva a quintais urbanos do nordeste brasileiro. Revista Espacios, v.36, n.16, 2015.

AMOROZZO, M. C. C. Agricultura tradicional, espaços de resistência e o prazer de plantar. Recife: SBEE, 2002.

AZEVEDO, E.; RIBAS, M. T. G. O. Estamos seguros? Reflexões sobre indicadores de avaliação de segurança alimentar e nutricional. Revista Nutrição. Campinas, v.29, n.2, 2016.

BARDIN, L. Análise de conteúdo. REGO, L. A. E PINHEIRO, A. (Trads). Lisboa: Edições 70, 2006. (Obra original publicada em 1977).

BEZERRA, I. ; SCHNEIDER, S. Produção e consumo de alimentos: o papel das políticas públicas na relação entre o plantar e o comer. Revista Faz Ciência, v.14, n.20, pp.35-61, 2012.

BEZERRA, I. Nesta terra, em se plantando tudo dá? Política de soberania e segurança alimentar e nutricional o meio rural paranaense, o caso do PAA. 2010. Tese (Doutorado em Ciências Sociais) - Universidade Federal do Rio Grande do Norte, Natal.

BRAGA, V. Cultura Alimentar: contribuições da antropologia da alimentação. Saúde em Revista, Piracicaba, v.6, n.13, 2004. 
BRASIL. ANVISA. Agência Nacional de Vigilância Sanitária. Programa de Análise de Resíduos de Agrotóxicos em Alimentos (PARA). Nota técnica sobre o risco de consumo de frutas e hortaliças cultivadas com agrotóxicos. Disponível em: $<$ http://portal.anvisa.gov.br/wps/wcm/connect/d0c9f980474575dd83f3d73fbc4c6735/nota+tecnica+ risco+consumo+frutas+e+hortalicas.pdf?MOD=AJPERES $>$ Acesso em 10 de fevereiro de 2016.

BRITO, M. A.; COELHO, M. F. Os quintais agroflorestais em regiões tropicais - unidades autossustentáveis. Revista Agricultura Tropical, Cuiabá, v.4, n.1, 2000.

CANTOR, K. M. Agricultura urbana: elementos valorativos sobre su sostentabilidad. Cuadernos de Desarollo Rural, v.7, n.65, 2010.

CARNEIRO, M. G. R. et al. Quintais produtivos: contribuição à segurança alimentar e ao desenvolvimento sustentável local na perspectiva da agricultura familiar ( $\mathrm{O}$ caso do assentamento Alegre, município de Quixeramobim/CE. Revista Brasileira de Agroecologia, n.8, v.2, 2013.

COLOMBO. Plano Municipal de Saúde 2014-2017, Prefeitura Municipal de Colombo, Paraná, 2013.

CORBETT, J. et al. Resumo: Cartografia para mudança - o aparecimento de uma prática nova. Participatory learning and action, n.54, 2006.

CRUZ NETO, O. O trabalho de campo como descoberta e criação. In: MINAYO, M. C. S., et al. Pesquisa Social: teoria, método e criatividade. Petrópolis: Vozes; 2004.

FREITAS, A. V. L. Plantas medicinais: um estudo etnobotânico nos quintais do Sítio Cruz, São Miguel, Rio Grande do Norte, Brasil. Revista Brasileira de Biociências, v.10, n.1, 2012.

GADELHA, E.; MALUF, R. S. Contribuições da produção para autoconsumo no acesso aos alimentos. Revista Democracia Viva, n.39, 2008.

GARCIA, R. W. D. Reflexos da globalização na cultura alimentar: considerações sobre as mudanças na alimentação urbana. Revista de Nutrição, v.16, n.4, 2003.

GRAZIANO DA SILVA, J. A industrialização e a Urbanização da Agricultura Brasileira. In: O agrário paulista. Revista São Paulo em Perspectiva. Fundação SEADE, v.7, n.3, 1993.

GRISA, C. Para além da alimentação: papéis e significados da produção para autoconsumo na agricultura familiar. Revista Extensão Rural, v. 14, n.1, 2007.

HARWOOD, R. R. Desarrollo de la pequena finca. San José, Costa Rica: IICA, 1986.

HERLIHY, P. H.; KNAPP, G. (Eds.). Maps of, by and for the Peoples of Latin America. Human Organization. Journal of the Society for Applied Anthropology. v.62, n.4, 2003.

HOUSE, P.; OCHOA, L. La diversidad de especies útiles em diez huertos em la aldea de Camalote, Honduras. In: LOK, R. (Ed.) Huertos caseros tradicionales de America Central: caracteristicas, 
beneficios e importancia desde un enfoque multidisciplinario. Costa Rica: CATIE, 1998, cap.3, p.61-79.

KEPPLE, A. W.; SEGALL-CORRÊA, A. M. Conceituando e medindo segurança alimentar e nutricional. Ciência \& Saúde Coletiva, n.16, v.1, 2011.

KHATOUNIAN, C. A. A reconstrução ecológica da agricultura. Botucatu: Agroecológica, 2001.

KINUPP, V. F.; LORENZI, H. Plantas Alimentícias Não Convencionais (PANC) no Brasil: guia de identificação. São Paulo: Instituto Plantarum de Estudos da Flora, 2014.

LACERDA, V. D. Quintais do Sertão do Ribeirão: agrobiodiversidade sob um enfoque etnobotânico. 2008. Monografia (Graduação em Ciências Biológicas)-Centro de Ciências Biológicas da Universidade Federal de Santa Catarina, Florianópolis, 2008.

MALUF, R. S.; MENEZES, F. Caderno 'Segurança Alimentar'. 2000. Disponível em:

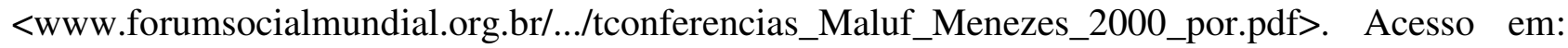
set. 2009.

MANZINI, E. J. Considerações sobre a elaboração de roteiro para entrevista semi-estruturada. In: MARQUEZINE, M. C.; ALMEIDA, M. A.; OMOTE, S. (Organizadores). Colóquios sobre pesquisa em educação especial. Londrina: Eduel, 2003, p.11-25.

MEDEIROS, N. S. Quintais urbanos e a situação de (in) segurança alimentar de famílias beneficiárias do Programa Bolsa Família, no município de Viçosa, Minas Gerais. 2015. Dissertação (Mestrado). Universidade Federal de Viçosa. 2015.

MENDONÇA NETO, O. A cartografia inovadora: uma reflexão sobre a cartografia social - ciência ou arte? Encuentro de Geógrafos de América Latína, Peru, 2013.

MENDONÇA. M. M.; LUNARDI, V. L. Conhecendo os quintais do Loteamento Ana Gonzaga - texto reflexivo. Rio de Janeiro, 2003, 14p. (mimeo)

MINAYO, M. C. S. Ciência, técnica e arte: o desafio da pesquisa social. In: DESLANDES, S. F.; NETO, O. C.; GOMES, R. Pesquisa Social: teoria, método e criatividade. Rio de Janeiro: Vozes, 2004.

MINISTÉRIO DO DESENVOLVIMENTO SOCIAL E COMBATE À FOME (MDS). Escala Brasileira de Insegurança alimentar - EBIA: análise psicométrica de uma dimensão da Segurança Alimentar e Nutricional. Estudo Técnico, n.1, 2014.

MONTEIRO, D.; MENDONÇA, M. M. Quintais na Cidade: a experiência de moradores da periferia do Rio de Janeiro. Revista Agriculturas, v.1, 2004.

MOSER, G. Psicologia Ambiental. Estudos de Psicologia, n.3, v.1, 1998.

MUtUAndo, InStituto GIRAMUNDO. A Cartilha Agroecológica. Botucatu, SP: Editora Criação Ltda., 2005. 
NAIR, P. R. Introduction to Agroforestry. Dordrecht: Kluwer Academic Publishers, 1993.

OLIVEIRA, C. A. Quintais agroflorestais mulheres redesenham espaços de produção e reprodução no Maranhão. Revista Agriculturas, v.6, n.4, 2009.

OLIVEIRA, Janine Patrícia Melo et al. Saúde/doença: as consequências da falta de saneamento básico. Informativo Técnico do Semiárido, v. 9, n. 2, p. 23-29, 2015.

ORLANDI, E. P. Análise de Discurso: princípios e procedimentos. Campinas, São Paulo: Pontes, 2009.

PACHECO, M. E. L. A realidade do modelo de produção agropecuária. COMSEA, Pinhais, 2013.

PLOEG, J. D. van der. Camponeses e Impérios alimentares - lutas por autonomia e sustentabilidade da era da globalização. Porto Alegre/RS: Editora UFRGS, 2008.

REDIN, E.; SILVEIRA, P. R. C. O campesinato revisitado: contribuição para compreensão da agricultura contemporânea. In: CONGRESSO SOCIEDADE BRASILEIRA DE ECONOMIA ADMINISTRAÇÃO E SOCIOLOGIA RURAL (SOBER), 48., 2010, Campo Grande/MG. Anais... Campo Grande, 2010.

REIS, D. S. O Rural e o Urbano no Brasil. In: ENCONTRO NACIONAL DE ESTUDOS POPULACIONAIS, MINAS GERAIS, XV, 2006, Minas Gerais. Anais... Minas Gerais: ABEP, 2006.

RICARTE-COVARRUBIAS, J. D.; FERRAZ, J. M. G.; BORGES, J. R. P. Segurança alimentar através da agricultura urbana: um estudo de caso em duas comunidades de baixa renda em Porto Ferreira/SP. Revista Brasileira de Agroecologia, v.6, n.3, p.62-80, 2011.

RIGON, S. A. et al. (Orgs). Soberania e segurança alimentar na construção da agroecologia: sistematização de experiências. Grupo de Trabalho em Soberania e Segurança Alimentar da Articulação Nacional de Agroecologia - GT SSA/ANA. 1.ed. Rio de Janeiro: FASE, 2010.

SABBATO, A. D. et al. Estatísticas rurais e a economia feminista: um olhar sobre o trabalho das mulheres. Brasília: MDA, 2009.

SEGALL-CORRÊA, A. M.; MARIN-LEON, L. A Segurança Alimentar no Brasil: Proposição e Usos da Escala Brasileira de Medida da Insegurança Alimentar (EBIA) de 2003 a 2009. Segurança Alimentar e Nutricional, Campinas, v.16, n.2, 2009.

SIVIERO, A. et al. Plantas medicinais em quintais urbanos de Rio Branco, Acre. Revista Brasileira de Plantas Medicinais. v.14, n.4, p.598-610, 2012.

TOLOI, G. G.; MANZINI, E. J. Etapas da estruturação de um roteiro de entrevista e considerações encontradas durante coleta dos dados. In: CONGRESSO BRASILEIRO MULTIDISCIPLINAR DE EDUCAÇÃO ESPECIAL, 8., 2013, Londrina. Anais...Londrina, 2013. 
VALENTE, F.. L. S. "Do combate à fome à segurança alimentar e nutricional: o direito à alimentação adequada". In:

São Paulo: Cortez Editora, 2002.

. O Direito Humano à Alimentação: desafios e Conquistas.

WINKLERPRINS, A.; OLIVEIRA, P. S. S. Urban Agriculture in Santarém, Pará, Brazil: diversity and circulation of cultivated plants in urban homegardens. Boletim do Museu Paraense Emílio Goeldi. Ciências Humanas. Belém, v. 5, n.

Artigo recebido em 15/05/2016. Aceito para publicação em 04/07/2016. 